\title{
INTERSPECIFIC HYBRIDIZATION WITHIN EUCALYPTUS (MYRTACEAE): SUBGENUS SYMPHYOMYRTUS, SECTIONS BISECTAE AND ADNATARIA
}

\author{
K. L. Delaporte,* J. G. Conran,t and M. Sedgley ${ }^{1, *}$ \\ *Department of Horticulture, Viticulture, and Oenology, Waite Agricultural Research Institute, Adelaide University, Glen Osmond, South \\ Australia 5064, Australia; and tDepartment of Environmental Biology, Adelaide University, Adelaide, South Australia 5005, Australia
}

\begin{abstract}
The potential for interspecific hybridization within the genus Eucalyptus was investigated through controlled pollination and measurement of seedling leaf morphology. Eucalyptus gillii and E. socialis (subgen. Symphyomyrtus sect. Bisectae ser. Subulatae) were used as the female parents, and pollen was sourced from 16 Eucalyptus species from a number of series within sections Bisectae and Adnataria (subgen. Symphyomyrtus). Thirty-four out of 36 crosses produced seeds; however, the percentage of seeds produced per flower pollinated varied considerably between crosses, as did germination percentage and seedling survival. At 3 mo of age, all surviving seedlings were measured for 15 leaf and stem characters. Multivariate analysis (ordination) of the data from each cross placed the seedlings in relation to their parents, with most crosses intermediate, albeit closer to the maternal parent. Successful hybridization occurred within sect. Bisectae ser. Subulatae and between ser. Subulatae and sect. Bisectae ser. Kruseanae, ser. Levispermae, ser. Curviptera, ser. Erectae and sect. Adnataria ser. Heterophloiae. In contrast, crosses between sect. Bisectae ser. Subulatae and sect. Adnataria ser. Aquilonares and ser. Melliodorae did not produce hybrids. Crosses between closely related species showed a greater degree of success than those between distant crosses, as did those between species with similar flower size.
\end{abstract}

Keywords: Eucalyptus, controlled pollination, multivariate analysis, ordination.

Introduction

The genus Eucalyptus L'Herit. contains over 700 species (Brooker and Kleinig 1999), and Pryor and Johnson (1971) proposed a classification into a hierarchy of subgenera, sections, series, subseries, superspecies, species, and subspecies, with groupings based on shared diagnostic morphological characteristics of the constituent taxa. Their classification was modified recently by Brooker (2000), and his system is the one followed here, although his inclusion of the genera Angophora and Corymbia within Eucalyptus sens. lat. is controversial (Ladiges and Udovicic 2000). Subgenera are reproductively isolated, and the likelihood of a successful cross increases with closeness of taxonomic affinity: intraseries crosses have a greater chance of success than interseries crosses, which themselves have a greater chance than intersectional crosses (Griffin et al. 1988). The potential for natural hybridization between species in the genus has been discussed by Ladiges (1997), with respect to genetic isolation between subgenera, sections, and some series and by Potts and Wiltshire (1997) regarding the evolutionary significance and taxonomic, structural, and physiological barriers to crossing. Some sections show greater affinity than others to crossing. For example, crosses between sections Bisectae and Adnataria have a high chance of success

\footnotetext{
${ }^{1}$ Author for correspondence; e-mail margaret.sedgley@ adelaide.edu.au.
}

Manuscript received February 2001; revised manuscript received June 2001.
(Ellis et al. 1991); however, wide hybridizations between distantly related sections (such as Bisectae and Maidenaria) are more likely to fail prefertilization. Hybrids may exhibit increased fitness (hybrid vigor) because of heterosis or decreased fitness because of the cross being too distant (Eldridge et al. 1993). This has implications for species improvement through crossing programs: potential crosses must be considered not only for the combination of desirable characters but also for taxonomic affinities and possible structural and physiological barriers to hybridization.

Controlled pollination, or manipulated/artificial hybridization, is used for the generation of interspecific hybrids for plant improvement and is widely used in the development of eucalypts for forestry and ornamental horticulture (Eldridge et al. 1993; Wirthensohn et al. 1999). The technique is also useful to test the probability of natural hybridization between species (Pryor 1951, 1956). Offspring from both natural and manipulated crosses may show morphology intermediate between the two parent taxa, as well as impaired reproductive capabilities and high levels of variability in the second generation offspring (Hopper 1995).

The standard technique of controlled pollination for eucalypts varies with researchers, but generally, the flowers are emasculated before anthesis, bagged to exclude external pollen, pollinated manually some days later, and left to develop. Research has found that emasculation of flower buds can discourage pollinators such as bees (Hodgson 1976), bagging can have a detrimental effect on the survival of the pollinated flowers (Pryor 1951), and successful pollination can be achieved with neither bagging nor emasculation (Beardsell et al. 1979). 
Table 1

Species Used in Controlled Pollinations

\begin{tabular}{|c|c|c|c|c|}
\hline Species & Section & Series & Flower size & Desirable characters \\
\hline Eucalyptus gillii Maiden & Bisectae & Subulatae & Medium & Floriferous, grey foliage and buds, long flowering season \\
\hline E. socialis F. Muell. ex Miq. & Bisectae & Subulatae & Medium & Floriferous, glaucous buds, flowers and leaves \\
\hline E. transcontinentalis Maiden & Bisectae & Subulatae & Medium & Numerous yellow buds and flowers \\
\hline E. caesia subsp. caesia Benth. & Bisectae & Curviptera & Large & Pink flowers, glaucous buds, weeping small habit \\
\hline E. macrocarpa Hook. & Bisectae & Curviptera & Extra large & Red flowers, glaucous buds, leaves and flowers \\
\hline E. oldfieldii F. Muell. & Bisectae & Curviptera & Medium & Round buds, small habit \\
\hline E. orbifolia F. Muell. & Bisectae & Curviptera & Medium & Glaucous buds, heart-shaped leaves \\
\hline E. websteriana Maiden & Bisectae & Curviptera & Small & Glaucous buds, heart-shaped or round leaves \\
\hline E. youngiana F. Muell. & Bisectae & Curviptera & Extra large & Yellow, peach, or red flowers; green, red, or purple buds \\
\hline E. kruseana F. Muell. & Bisectae & Kruseanae & Medium & Grey round foliage, small habit, long flowering season \\
\hline E. gardneri Maiden & Bisectae & Levispermae & Medium & Floriferous, blue foliage \\
\hline E. eremophila (Diels) Maiden & Bisectae & Erectae & Medium & Floriferous, pink flowers \\
\hline E. steedmanii C. Gardner & Bisectae & Erectae & Large & Yellow square buds and flowers, small neat habit \\
\hline E. pruinosa Schauer & Adnataria & Aquilonares & Small & Numerous cream terminal flowers \\
\hline E. polyanthemos Schauer & Adnataria & Heterophloiae & Small & Numerous terminal flowers, grey leaves \\
\hline E. sideroxylon Cunn. ex Wools & Adnataria & Melliodorae & Small & Pink buds and flowers \\
\hline
\end{tabular}

Note. Desirable characters and phylogenetic placement of each species within the Eucalyptus genus (subgenus Symphyomyrtus), according to the classification of Brooker (2000), are included. Flower size (from stigma to base of hypanthium): small ( $<8 \mathrm{~mm}$ long), medium (9-18 mm long), large (19-25 mm long), extra large (>25 mm long).

Length of style compared with potential pollen tube length has been proposed as the cause of some previous failed interspecific hybridization attempts, such as between long-styled E. caesia and short-styled E. sideroxylon, E. leucoxylon, and E. pulverulenta, and short-styled E. nitens and long-styled E. globulus (Pryor 1956; Beardsell et al. 1979; Tibbits 1988, 1989; Gore et al. 1990). The cross was successful only when the style from the male species flower was longer than that of the female species, leading to the conclusion that the potential length of the pollen tube is directly related to the length of the style of that species.

In this study, we utilized controlled pollination as a method to produce hybrids with increased merit as ornamentals. Each species was selected for its ornamental characters, specifically, tree habit and vigor; floriferousness; inflorescence insertion; flower size, shape, and color; and leaf size, shape, and color. Flower size, while an important ornamental character, may have implications for the success of the pollination, and this was an important consideration in species selection. Species were also selected on the basis of their taxonomic affinity to the female parent species (sect. Bisectae ser. Subulatae): three species are from the same series (sect. Bisectae ser. Subulatae), six are from a closely related series (sect. Bisectae ser. Curviptera), four are from distantly related series (sect. Bisectae ser. Kruseanae, ser. Levispermae, ser. Erectae), and three are from different series within a different section (sect. Adnataria ser. Aquilonares, ser. Heterophloiae, ser. Melliodorae) (table 1). All species are from subgenus Symphyomyrtus (Brooker 2000). Hybrid status was determined through seedling morphological character analysis, and results were used to assess the likeli-

Table 2

Seedling Morphological Characters Measured for Leaf Node 7 (3 mo after Germination)

\begin{tabular}{|c|c|c|}
\hline Code & Character & Description \\
\hline LSH & Leaf shape & Linear $(0)$, lanceolate (1), ovate (2), cordate/heart shaped (3), orbicular (4) \\
\hline LST & Leaf tip & Acuminate $(0)$, acute $(1)$, mucronulate $(2)$, obtuse (3), truncate (4), emarginate (5) \\
\hline LSB & Leaf base & Attenuate (0), oblique (1), obtuse (2), cordate (3) \\
\hline LLE & Leaf length & $\mathrm{mm}$ \\
\hline LWI & Leaf width & $\mathrm{mm}$ \\
\hline LSW & Leaf surface wax & Shining $(0)$, dull (1), glaucous (2), very glaucous (3) \\
\hline LEA & Leaf surface & Concolorous (0), discolorous (1) \\
\hline LSM & Leaf surface & Smooth $(0)$, not smooth $(1)$ \\
\hline LPS & Leaf attachment & Sessile $(0)$, petiolate $(1)$ \\
\hline LPL & Leaf petiole & $\mathrm{mm}$ \\
\hline LPO & Leaf insertion & Opposite (0), alternate (1) \\
\hline LCO & Leaf color & Light green $(0)$, green $(1)$, grey green $(2)$, blue green $(3)$, dark green $(4)$ \\
\hline SSH & Stem shape & Square $(0)$, angular $(1)$, round $(2)$ \\
\hline STE & Stem form & Single $(0)$, branching $(1)$ \\
\hline SSM & Stem surface & Smooth $(0)$, not smooth $(1)$ \\
\hline
\end{tabular}


Table 3

Summary of Data for Eucalyptus gillii

\begin{tabular}{|c|c|c|c|c|c|c|c|c|c|c|c|c|}
\hline Male parent & Series & Section & Flower size $^{a}$ & $\begin{array}{l}\text { No. of } \\
\text { flowers } \\
\text { pollinated }\end{array}$ & $\begin{array}{l}\text { No. of seeds } \\
\text { produced } \\
\text { per flower } \\
\text { pollinated }\end{array}$ & $\begin{array}{c}\text { Seeds } \\
\text { germinated } \\
(\%)\end{array}$ & $\begin{array}{c}\text { Seedlings } \\
\text { surviving } \\
\text { to measurement } \\
(\%)\end{array}$ & $\begin{array}{l}\text { No. of } \\
\text { seedlings } \\
\text { measured }\end{array}$ & $\begin{array}{c}\text { No. of } \\
\text { contaminants }\end{array}$ & $\begin{array}{c}\text { No. of } \\
\mathrm{F}_{1} \text { hybrids }^{\mathrm{c}}\end{array}$ & $\begin{array}{c}\text { Hybrid } \\
\text { seedlings } \\
(\%)\end{array}$ & $\begin{array}{c}\text { No. of } \\
\text { hybrid } \\
\text { seedlings } \\
\text { per flower } \\
\text { pollinated }\end{array}$ \\
\hline E. gillii (intra) ${ }^{\mathrm{d}}$ & Bisectae & Subulatae & Medium & 100 & 1.22 & 96.7 & 57.6 & $68^{e}$ & $n a^{e}$ & $n a^{e}$ & $\mathrm{na}^{\mathrm{e}}$ & $\mathrm{na}^{\mathrm{e}}$ \\
\hline E. transcontinentalis & Bisectae & Subulatae & Medium & 79 & 0.81 & 73.4 & 44.5 & 35 & 10 & 25 & 71.4 & 0.32 \\
\hline E. socialis & Bisectae & Subulatae & Medium & 110 & 0.83 & 100.0 & 41.8 & 38 & 0 & 38 & 100.0 & 0.35 \\
\hline E. caesia & Bisectae & Curviptera & Large & 119 & 0.05 & 100.0 & 100.0 & 6 & 6 & 0 & 0.0 & 0.00 \\
\hline E. macrocarpa & Bisectae & Curviptera & Extra large & 190 & 0.06 & 41.7 & 0.00 & 0 & 0 & 0 & 0.0 & 0.00 \\
\hline E. oldfieldii & Bisectae & Curviptera & Medium & 139 & 0.76 & 58.5 & 87.1 & 54 & 1 & 53 & 98.5 & 0.38 \\
\hline E. orbifolia & Bisectae & Curviptera & Medium & 141 & 0.96 & 86.7 & 8.6 & 10 & 9 & 1 & 10.0 & 0.07 \\
\hline E. websteriana & Bisectae & Curviptera & Small & 136 & 0.10 & 61.5 & 12.5 & 1 & 1 & 0 & 0.0 & 0.00 \\
\hline E. youngiana & Bisectae & Curviptera & Extra large & 189 & 0.21 & 30.8 & 33.4 & 4 & 4 & 0 & 0.0 & 0.00 \\
\hline E. kruseana & Bisectae & Kruseanae & Medium & 128 & 0.52 & 84.8 & 70.4 & 38 & 0 & 38 & 100.0 & 0.30 \\
\hline E. gardnerii & Bisectae & Levispermae & Medium & 162 & 0.40 & 81.3 & 80.8 & 42 & 0 & 42 & 100.0 & 0.26 \\
\hline E. eremophila & Bisectae & Erectae & Medium & 130 & 0.18 & 87.0 & 55.0 & 11 & 11 & 0 & 0.0 & 0.00 \\
\hline E. steedmanii & Bisectae & Erectae & Large & 116 & 0.02 & 0.00 & 0.00 & 0 & 0 & 0 & 0.0 & 0.00 \\
\hline E. pruinosa & Adnataria & Aquilonares & Medium & 60 & 0.00 & 0.00 & 0.00 & 0 & 0 & 0 & 0.0 & 0.00 \\
\hline E. polyanthemos & Adnataria & Heterophloiae & Small & 100 & 0.48 & 43.8 & 28.6 & 6 & 0 & 6 & 100.0 & 0.06 \\
\hline E. sideroxylon & Adnataria & Melliodorae & Medium & 118 & 0.01 & 100.0 & 100.0 & 1 & 1 & 0 & 0.0 & 0.00 \\
\hline
\end{tabular}

Source. Classification according to Brooker (2000).

a Stigma to hypanthium (refer to table 1).

${ }^{\mathrm{b}}$ Number of individual seedlings grouping with open-pollinated offspring from intraspecific mating of female parent according to multidimensional scaling (MDS) ordination.

${ }^{c}$ Number of individual seedlings grouping separately to open-pollinated offspring from intraspecific mating of female parent or male parent according to MDS ordination.

${ }^{d}$ Seedlings produced by controlled pollination between two E. gillii individuals.

${ }^{\mathrm{e}}$ Not applicable in this study because seedlings not interspecific $\mathrm{F}_{1}$ hybrids. 
hood of successful crosses between series in sect. Bisectae and between sect. Bisectae and sect. Adnataria.

\section{Material and Methods}

\section{Plant Material}

The 16 species used in the study were selected on the basis of one or more desirable ornamental characters, as well as their phylogenetic relationships to the female parent species, and represent a range of flower sizes and plant forms. Two species, Eucalyptus gillii and E. socialis, were used as the female parents, and 16 species were used as the male parents (table 1). Plants were sourced from the Waite Arboretum, Ade-

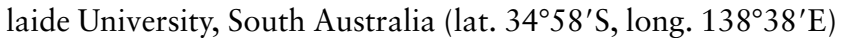
and the Monarto Woodland, Callington, South Australia (lat. $35^{\circ} 58^{\prime}$ S, long. $\left.139^{\circ} 25^{\prime} \mathrm{E}\right)$.

\section{Controlled Pollination}

Pollen was collected from the male parent species over a 12 mo period and stored at $-20^{\circ} \mathrm{C}$ until required (Eldridge et al. 1993). Flowers were collected just before anthesis at operculum lift, and the anthers were removed and dried over silica gel at room temperature. Viability of pollen was checked by germination on agar medium for $24 \mathrm{~h}$. All samples showed greater than $50 \%$ viability. Two plants from each of the female parent species were used, with between 50 and 200 flowers pollinated for each male parent. Flower buds were emasculated at operculum lift, all umbels on one branch were pollinated by the same male parent, and each was umbel tagged. Pollen was applied to the stigma with a small paintbrush 1 wk later, and the pollination step was repeated every $3 \mathrm{~d}$ until every emasculated flower was pollinated at least twice. The flowers were not isolated, and although this may increase the risk of contamination with undesired pollen, the flowering umbels of each female parent species were very difficult to bag due to their arrangement on the stem. All unpollinated flowers in the umbel were removed to reduce the chance of self-pollination.

Capsules were harvested 8 mo after pollination, placed individually in paper envelopes, and placed in a warm, dry room at $30^{\circ} \mathrm{C}$ for up to $4 \mathrm{wk}$ to enable the capsules to open. Seeds produced by natural open-pollination from each of the 16 parent species were also collected. All seeds within a capsule were placed individually in plastic vials and soaked for $24 \mathrm{~h}$ in $3000 \mathrm{ppm}$ gibberellic acid $\left(\mathrm{GA}_{3}\right)$ to aid germination (Ostrowska et al. 1998). Seeds were sown in 25 -mm pots containing sand and pine bark in a $1: 2$ ratio and covered with a thin layer of vermiculite, with one seed per pot. Each pot was labeled according to the cross, capsule, and seed number and randomly placed in a plastic tray, with a total of 40 pots per tray. Each tray was covered in a plastic bag to maintain humidity that was removed when the majority of the seeds in the tray had germinated, ca. 7-14 d after sowing. The seeds and pots were not replicated due to the varying numbers of seeds for each cross. Seedlings were grown in a glasshouse during spring, under conditions of natural daylength and mean, maximum, and minimum temperatures of $18^{\circ} \pm 3^{\circ} \mathrm{C}$ to $25^{\circ} \pm 3^{\circ} \mathrm{C}$. A liquid fertilizer (Aquasol) was applied fortnightly.

\section{Seedling Morphology}

Each seedling was measured for 15 numerical, binary, or ordered multistate leaf and stem characters on fully expanded leaves at the seventh node above the cotyledons (table 2) 3 mo after germination. All surviving seedlings were included in the analysis. Twenty-five open-pollinated offspring from each parent species were measured for the above characters 3 mo after germination.

\section{Data Analysis}

The seedling morphological data were analyzed using the PATN analysis package (Belbin 1994) in order to determine the similarity between progeny and parent species. Each combination was analyzed separately, with progeny compared to open-pollinated offspring of the male and female parents.

A pairwise dissimilarity matrix between the individual seedlings within each cross, based on the morphological characters measured, was generated using Gower's metric, a rangestandardized Manhattan distance. Gower's metric was preferred as the association measure, as it is robust for hierarchical taxonomic pattern analysis with mixed data types, especially when the data show a unimodal or nonlinear response to the underlying ordination space (Faith 1991; Podani 1999). Seedlings sharing similar morphology were grouped together using group average cluster analysis (UPGMA), and the relationships between these groups were visualized using nonhierarchical ordination multidimensional scaling (MDS) with semistrong hybrid analysis (Minchin 1987).

\section{Results}

The summary data (table 3) for the 16 crosses with Eucalyptus gillii as the female parent showed that the number of seeds produced per flower pollinated ranged from 0.01 seeds

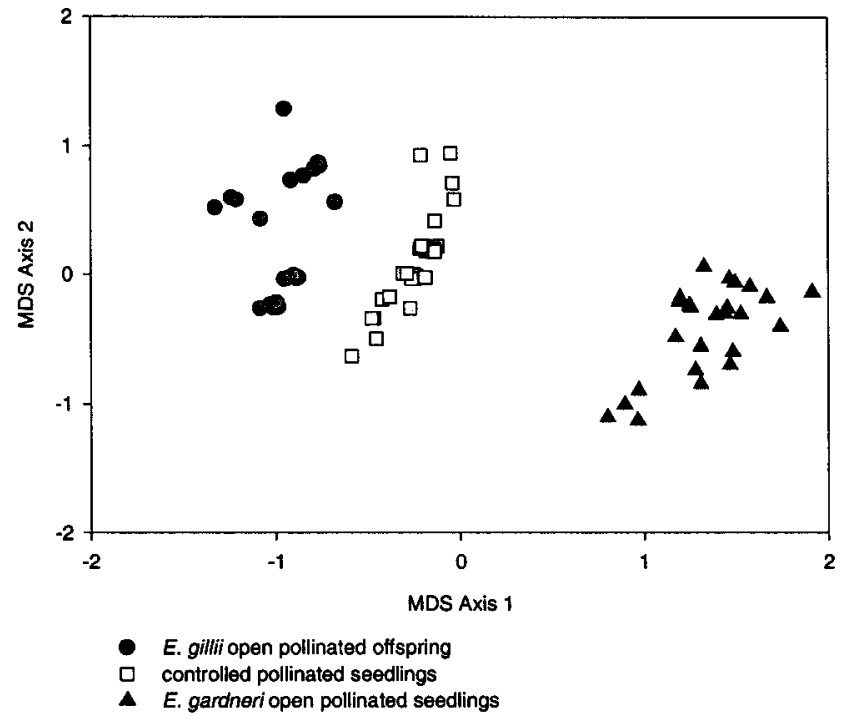

Fig. 1 Multidimensional scaling ordination of E. gillii $\times$ E. gardneri seedlings from controlled pollination and open-pollinated seedlings from each parent species. 
per flower for E. gillii $\times$ E. sideroxylon to 0.96 seeds per flower for E. gillii $\times$ E. orbifolia. The intraspecific cross between two related $E$. gillii individuals produced 1.22 seeds per flower pollinated. The cross with E. pruinosa as the male parent did not produce seeds. The percentage of seeds germinated ranged from $30.8 \%$ for E. gillii $\times$ E. youngiana to $100 \%$ for E. gillii $\times$ E. socialis. The percentage of seedlings surviving to 3 mo ranged from $8.6 \%$ for E. gillii $\times$ E. orbifolia to $87 \%$ for E. gillii $\times$ E. oldfieldii and $100 \%$ for E. gillii $\times$ E. sideroxylon. The intraspecific cross showed a $57.6 \%$ seedling survival rate. Crosses with E. pruinosa, E. steedmanii, and E. macrocarpa did not produce seedlings.

All seedlings from crosses with E. caesia, E. eremophila, E. sideroxylon, E. websteriana, and E. youngiana as the male parent clustered with open-pollinated offspring of E. gillii. Some seedlings from crosses between E. gillii and E. orbifolia (9), E. transcontinentalis (10), and E. oldfieldii (1) clustered with open-pollinated offspring of E. gillii, with the remaining seedlings from each cross clustering between open-pollinated offspring of both parents. All seedlings from crosses with $E$. gardneri, E. kruseana, E. polyanthemos, and E. socialis clustered between the open-pollinated offspring of the female and male parents, suggesting intermediacy.

Similarly, the MDS scatter plots for each cross reflected the dendrogram groupings (figs. 1-7). The stress values for all MDS analyses were between $1.17 \%$ and $12.22 \%$. The stress measure indicates how well the position of the seedlings relative to each other (based on multicharacter data) has been portrayed in a two-dimensional scatter plot, with stress values below $20 \%$ considered to represent an acceptable level of distortion (Belbin 1994).

The summary data (table 4) for the 16 crosses with E. socialis as the female parent showed that the number of seeds produced per flower pollinated ranged from 0.09 seeds per flower for E. socialis $\times$ E. macrocarpa to 1.52 seeds per flower for E. socialis $\times$ E. steedmanii. The intraspecific cross, be-

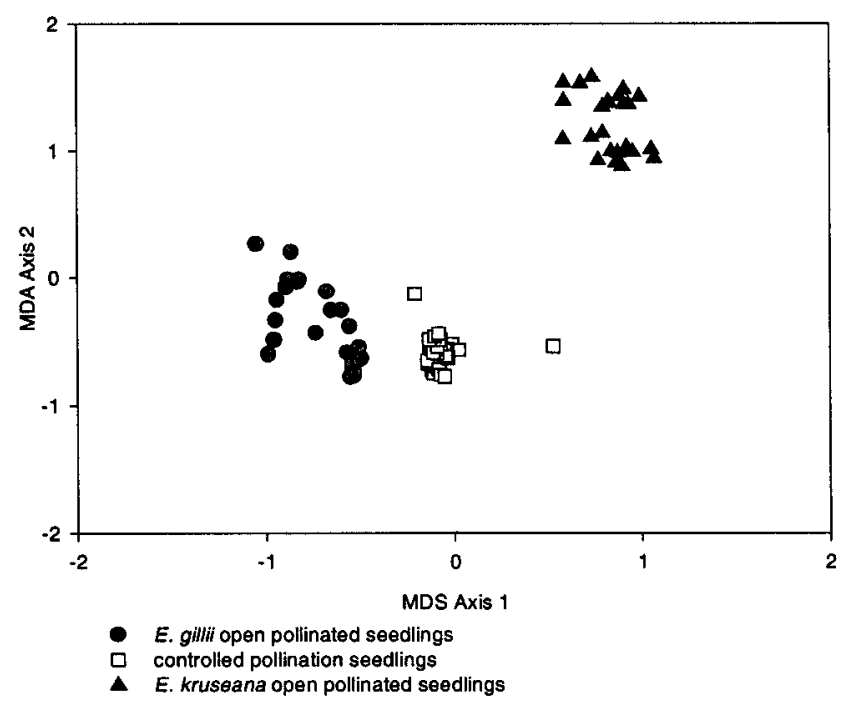

Fig. 2 Multidimensional scaling ordination of E. gillii $\times$ E. kruseana seedlings from controlled pollination and open-pollinated seedlings from each parent species.

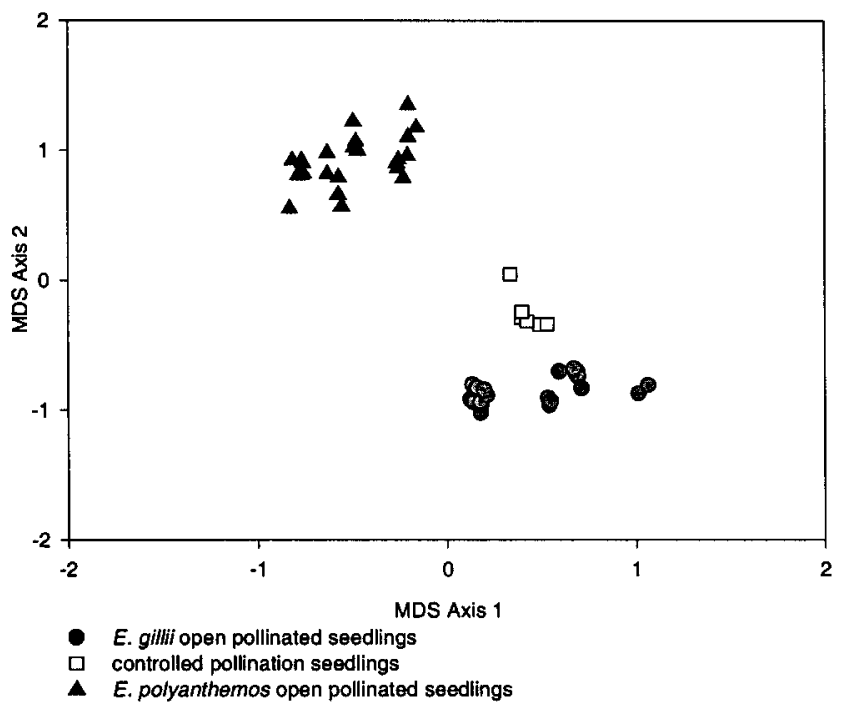

Fig. 3 Multidimensional scaling ordination of E. gillii $\times$ E. polyanthemos seedlings from controlled pollination and open-pollinated seedlings from each parent species.

tween two related E. socialis individuals, produced 0.38 seeds per flower pollinated. The cross with E. pruinosa as the male parent did not produce seeds. The percentage of seeds germinated ranged from $5.0 \%$ for E. socialis $\times$ E. youngiana to $40 \%$ for E. socialis $\times$ E. macrocarpa. The percentage of seedlings surviving to $3 \mathrm{mo}$ ranged from $50 \%$ for $E$. socialis $\times$ E. gardneri to $100 \%$ for five crosses, with all but three showing greater than $75 \%$ seedling survival. The intraspecific cross showed a $90.6 \%$ seedling survival rate.

Cluster analysis of E. socialis $\times$ E. caesia, E. socialis $\times E$. macrocarpa, E. socialis $\times$ E. oldfieldii, E. socialis $\times$ E. orbifolia, E. socialis $\times$ E. websteriana, E. socialis $\times$ E. youn-

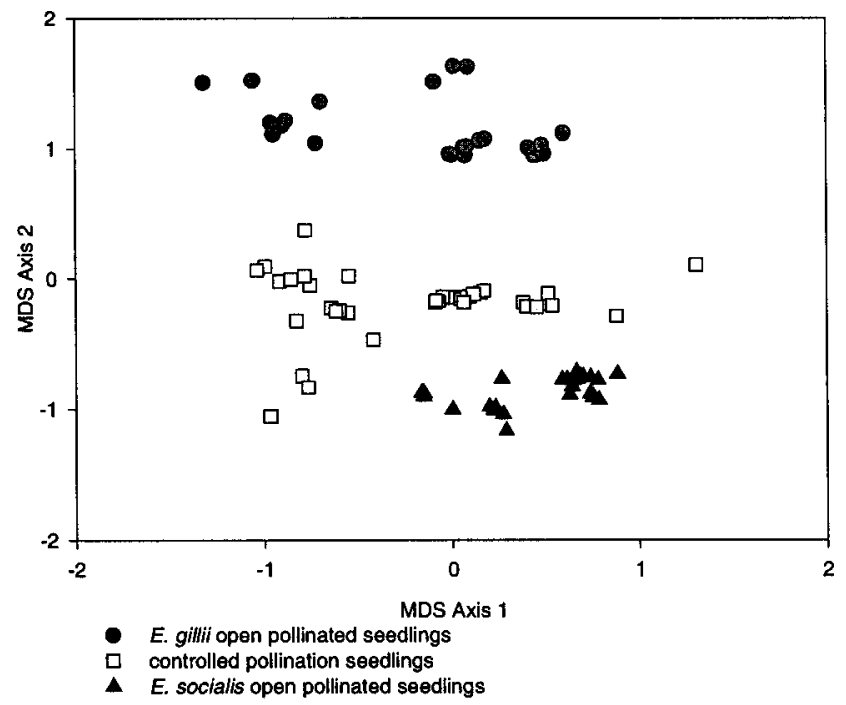

Fig. 4 Multidimensional scaling ordination of E. gillii $\times$ E. socialis seedlings from controlled pollination and open-pollinated seedlings from each parent species. 


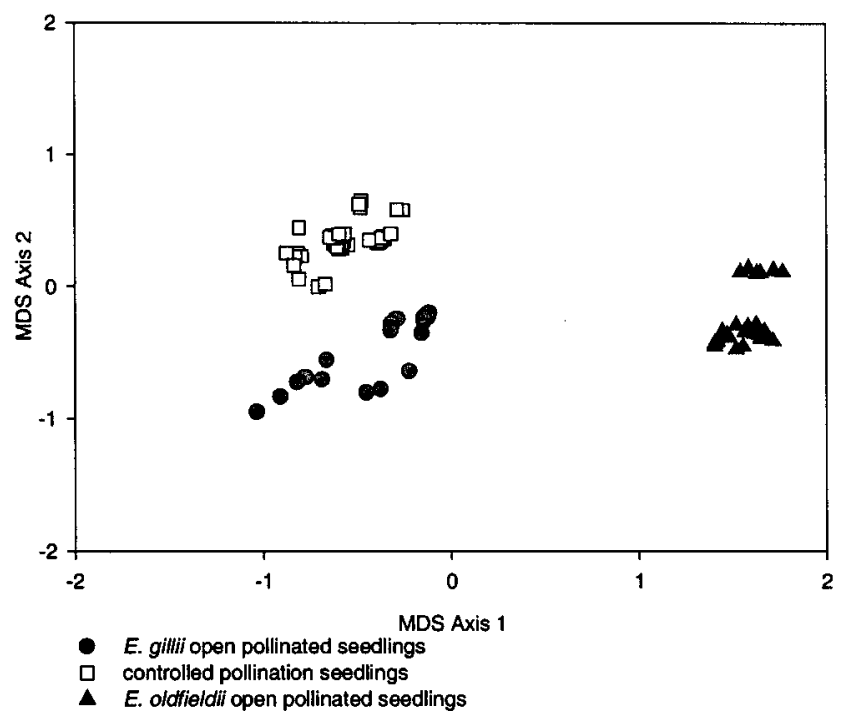

Fig. 5 Multidimensional scaling ordination of E. gillii $\times$ E. oldfieldii seedlings from controlled pollination and open-pollinated seedlings from each parent species.

giana, E. socialis $\times$ E. eremophila, E. socialis $\times$ E. polyanthemos, and E. socialis $\times$ E. sideroxylon divided the seedlings into two clusters: open-pollinated female parent offspring with all seedlings and all open-pollinated offspring from the male parent. Eucalyptus socialis $\times$ E. gardneri and crosses between E. gillii and E. kruseana and E. transcontinentalis and E. steedmanii were each divided into three clusters, with around half the seedlings clustered separately to the open-pollinated offspring of either parent and the other half clustered with the open-pollinated offspring of the female parent. The openpollinated offspring of the male parent were always clustered together. The MDS scatter plots for the interspecific crosses reflected the dendrogram groupings, and in the intraspecific cross, the seedlings were scattered across the plot (figs. 8-11).

\section{Discussion}

This study has confirmed and extended the findings of Ellis et al. (1991) that some species within Bisectae and Adnataria will hybridize with relative ease. Our crossing program produced over 400 seedlings from the two female parent species and the 16 male parent species. Cluster and ordination analysis of all seedlings, based on seedling morphology, placed ca. 50\% between their parents on both the dendrograms and the ordination plots. Crosses between species from the same series, Eucalyptus gillii, E. socialis, and E. transcontinentalis (ser. Subulatae), produced 76 hybrid seedlings out of 90 seedlings measured, while crosses with E. gillii and E. socialis and species from the next closest series, ser. Curviptera, produced only 54 out of 118 , with 53 of these from one cross $($ E. gillii $\times$ E. oldfieldii). Most species selected from ser. Curviptera have large to very large flowers, and this may have contributed to the low success rate, with the exception of E. gillii $\times$ E. oldfieldii, where the flowers of both parents were medium in size. Other crosses where flowers of both parents were of similar

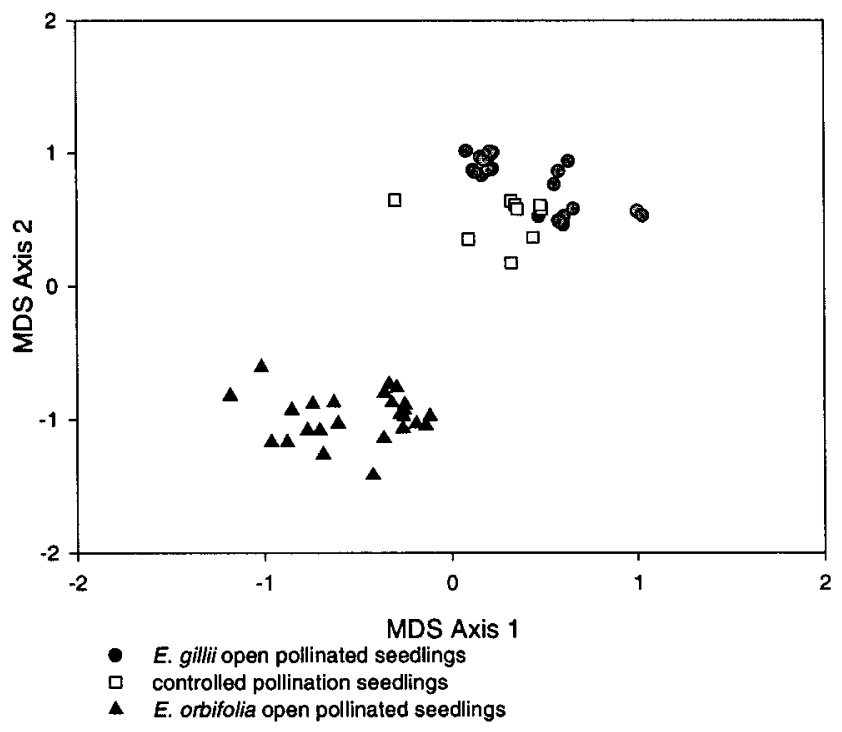

Fig. 6 Multidimensional scaling ordination of E. gillii $\times$ E. orbifolia seedlings from controlled pollination and open-pollinated seedlings from each parent species.

flower size showed high numbers of hybrids produced out of seedlings measured, such as E. gillii and E. kruseana (distantly related series), with 38 hybrids out of 38 seedlings measured, and E. gillii $\times$ E. gardneri (distantly related series), with 42 hybrids out of 42 seedlings measured. Six hybrid seedlings were produced from the intersectional cross between E. gillii (sect. Bisectae) and E. polyanthemos (sect. Adnataria): the flower size for E. polyanthemos is small, while E. gillii is medium.

In almost all of the MDS plots, the hybrid seedlings, although intermediate between the parents, were placed closer

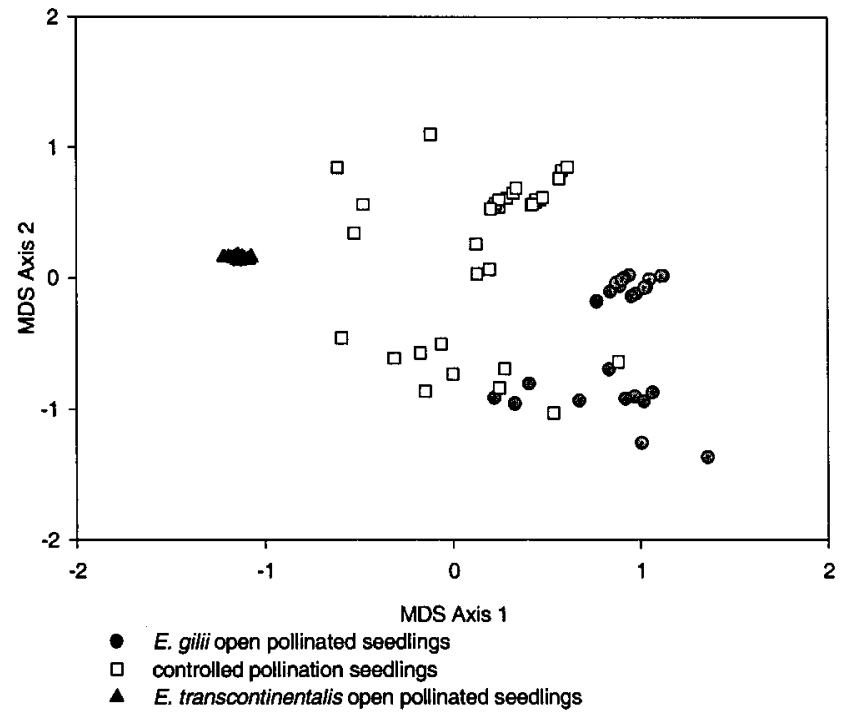

Fig. 7 Multidimensional scaling ordination of E. gillii $\times$ E. transcontinentalis seedlings from controlled pollination and openpollinated seedlings from each parent species. 
Table 4

Summary of Data for Eucalyptus socialis

\begin{tabular}{|c|c|c|c|c|c|c|c|c|c|c|c|c|}
\hline Male parent & Series & Section & Flower size ${ }^{a}$ & $\begin{array}{l}\text { No. of } \\
\text { flowers } \\
\text { pollinated }\end{array}$ & $\begin{array}{c}\text { No. of seeds } \\
\text { produced } \\
\text { per flower } \\
\text { pollinated }\end{array}$ & $\begin{array}{c}\text { Seeds } \\
\text { germinated } \\
(\%)\end{array}$ & $\begin{array}{c}\text { Seedlings } \\
\text { surviving to } \\
\text { measurement } \\
(\%)\end{array}$ & $\begin{array}{l}\text { No. of } \\
\text { seedlings } \\
\text { measured }\end{array}$ & $\begin{array}{l}\text { No. of } \\
\text { contaminants }\end{array}$ & $\begin{array}{l}\text { No. of } F_{1} \\
\text { hybrids }^{c}\end{array}$ & $\begin{array}{l}\text { Hybrid } \\
\text { seedlings } \\
(\%)\end{array}$ & $\begin{array}{c}\text { No. of } \\
\text { hybrid } \\
\text { seedlings } \\
\text { per flower } \\
\text { pollinated }\end{array}$ \\
\hline E. socialis (intra) ${ }^{\mathrm{d}}$ & Bisectae & Subulatae & Medium & 48 & 0.38 & 61.1 & 90.9 & $10^{\mathrm{e}}$ & $n a^{e}$ & $n a^{e}$ & $\mathrm{na}^{\mathrm{e}}$ & $n a^{\mathrm{e}}$ \\
\hline E. transcontinentalis & Bisectae & Subulatae & Medium & 44 & 1.41 & 19.4 & 100.0 & 12 & 3 & 9 & 75.0 & 0.21 \\
\hline E. gillii & Bisectae & Subulatae & Medium & 63 & 0.32 & 25.0 & 100.0 & 5 & 1 & 4 & 80.0 & 0.06 \\
\hline E. caesia & Bisectae & Curviptera & Large & 73 & 0.36 & 30.8 & 75.0 & 6 & 6 & 0 & 0.0 & 0.00 \\
\hline E. oldfieldii & Bisectae & Curviptera & Medium & 100 & 0.55 & 21.8 & 83.3 & 10 & 10 & 0 & 0.0 & 0.00 \\
\hline E. orbifolia & Bisectae & Curviptera & Medium & 43 & 0.30 & 38.5 & 100.0 & 5 & 5 & 0 & 0.0 & 0.00 \\
\hline E. websteriana & Bisectae & Curviptera & Small & 100 & 1.42 & 14.1 & 90.0 & 18 & 18 & 0 & 0.0 & 0.00 \\
\hline E. youngiana & Bisectae & Curviptera & Extra & 78 & 0.53 & 5.0 & 100.0 & 2 & 2 & 0 & 0.0 & 0.00 \\
\hline E. kruseana & Bisectae & Kruseanae & Medium & 62 & 0.45 & 35.7 & 80.0 & 8 & 5 & 3 & 37.5 & 0.05 \\
\hline E. gardnerii & Bisectae & Levispermae & Medium & 100 & 0.49 & 20.4 & 50.0 & 5 & 2 & 3 & 60.0 & 0.03 \\
\hline E. eremophila & Bisectae & Erectae & Medium & 65 & 0.28 & 38.9 & 100.0 & 7 & 7 & 0 & 0.0 & 0.00 \\
\hline E. steedmanii & Bisectae & Erectae & Large & 25 & 1.52 & 39.5 & 60.0 & 9 & 5 & 4 & 44.5 & 0.16 \\
\hline E. pruinosa & Adnataria & Aquilonares & Medium & 54 & 0.00 & 0.0 & 0.0 & 0 & 0 & 0 & 0.0 & 0.00 \\
\hline E. polyanthemos & Adnataria & Heterophloiae & Small & 63 & 0.78 & 22.5 & 81.8 & 9 & 9 & 0 & 0.0 & 0.00 \\
\hline
\end{tabular}

Source. Classification according to Brooker (2000).

a Stigma to hypanthium (refer to table 1).

Number of individual seedlings grouping with open-pollinated offspring from intraspecific mating of female parent according to multidimensional scaling (MDS) ordination.

Number of individual seedlings grouping separately to open-pollinated offspring from intraspecific mating of female parent or male parent according to MDS ordination.

Seedlings produced by controlled pollination between two E. gillii individuals.

${ }^{\mathrm{e}}$ Not applicable in this study because seedlings not interspecific $\mathrm{F}_{1}$ hybrids. 


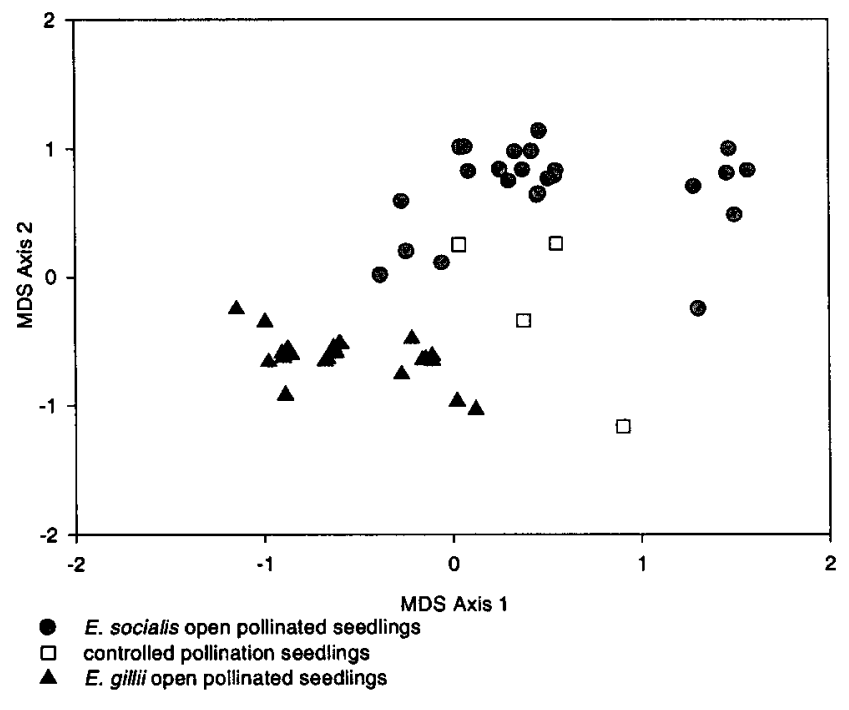

Fig. 8 Multidimensional scaling ordination of E. socialis $\times$ E. gillii seedlings from controlled pollination and open-pollinated seedlings from each parent species.

to seedlings from the maternal species. Ordination places seedlings, which are most similar to each other based on all of their characteristics, closer together in the ordination space. This means that, although the hybrids were intermediate for a number of features (such as leaf shape, leaf length, leaf width, leaf color, and stem shape), there were others for which in several crosses (e.g., E. gillii $\times$ E. gardneri, E. gillii $\times$ E. kruseana) there was apparent strong maternal inheritance in some characters (such as leaf surface wax, leaf sessile or petiolate, leaf petiole length) at least in the seedling stage, resulting in the placement of the hybrid seedlings closer to those of the

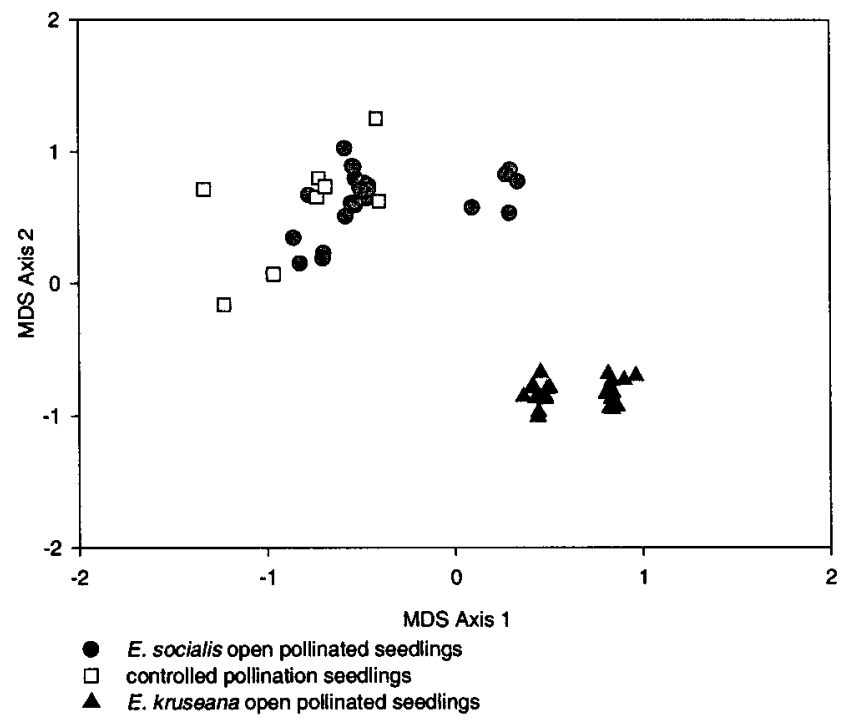

Fig. 9 Multidimensional scaling ordination of E. socialis $\times E$. kruseana seedlings from controlled pollination and open-pollinated seedlings from each parent species.

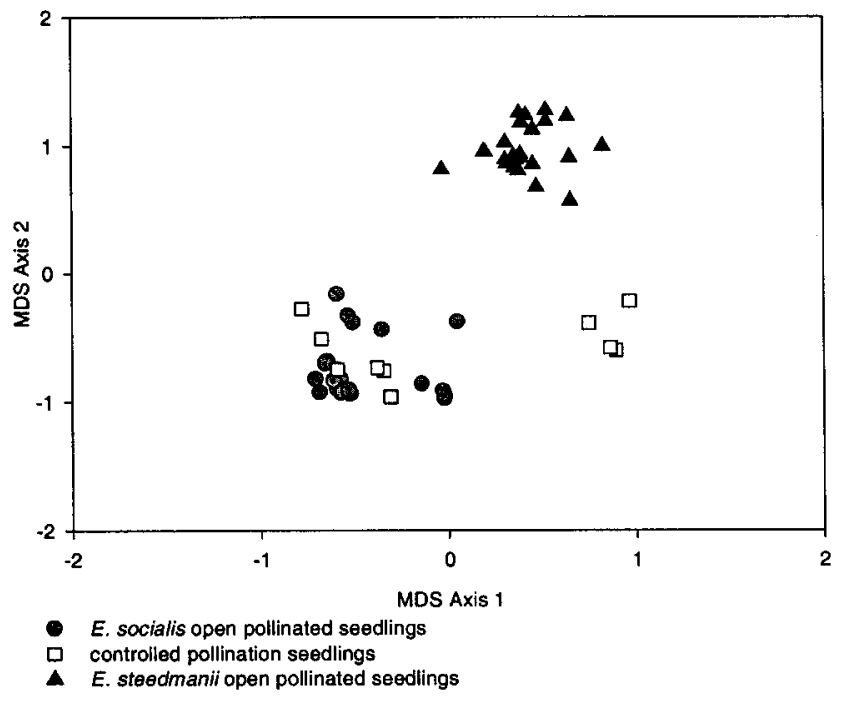

Fig. 10 Multidimensional scaling ordination of E. socialis $\times E$. steedmanii seedlings from controlled pollination and open-pollinated seedlings from each parent species.

maternal parent. This early seedling maternal inheritance for at least some features has also been noted in E. grandis $\times E$. nitens hybrids (Shelbourne et al. 1999) and may disappear as the seedlings mature and the adult, generally more intermediate features develop.

Species used in this study showed a range of flower sizes, from smaller than the female parent species to much larger. This enabled further information regarding the effect of length of style versus potential pollen tube length to be gathered. In addition, most highly ornamental Eucalyptus species have very large flowers but relatively few per tree. Thus, by crossing a large-flowered species with a smaller-flowered species that has many hundreds of flowers, a hybrid with many medium-sized flowers might be produced. Observations of the morphology of these species indicated that a higher degree of hybridization success was realized between species with similar flower sizes than between species with dissimilar flower sizes. Flowers from the female parents, E. gillii and E. socialis, and pollen donors, E. kruseana, E. transcontinentalis, E. oldfieldii, E. gardneri, E. eremophila, and E. orbifolia, are between 9 and $18 \mathrm{~mm}$ long (from stigma to base of hypanthium), and crosses between these species produced the most hybrids. The flowers of $E$. polyanthemos, E. sideroxylon, E. pruinosa, and E. websteriana are less than $8 \mathrm{~mm}$ long, and only the E. gillii $\times E$. polyanthemos cross produced hybrids. Flowers from E. caesia and E. steedmanii are between 19 and $25 \mathrm{~mm}$ long, and those from E. macrocarpa and E. youngiana are greater than $25 \mathrm{~mm}$ long; only four hybrid offspring were produced from these crosses, all from E. socialis $\times$ E. steedmanii.

Seed production varied across all crosses, from greater than that produced by the intraspecific cross to much less. Germination rates also varied, although more seeds germinated with E. gillii as the female than for E. socialis. In contrast, high seedling mortality was observed in seedlings from crosses involving E. gillii as the female parent, which may have been caused by lethal gene combinations or incompatible crosses, 


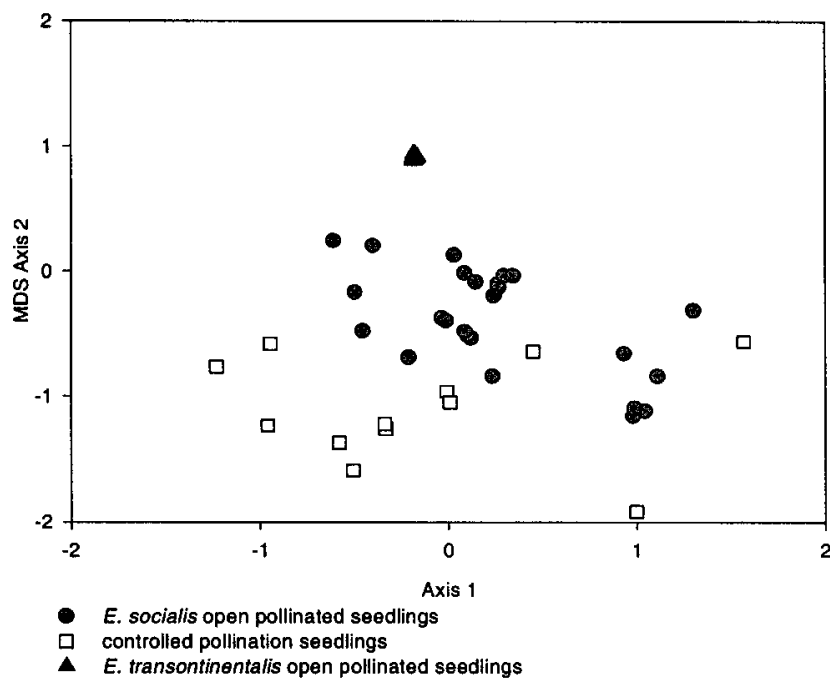

Fig. 11 Multidimensional scaling ordination of E. socialis $\times E$. transcontinentalis seedlings from controlled pollination and openpollinated seedlings from each parent species.

resulting in low seedling vigor and disease susceptibility, whereas most seedlings involving E. socialis had survived to 3 mo of age.

The occurrence of both natural and artificial hybrids within Eucalyptus was summarized by Griffin et al. (1988), who listed 25 hybrids involving species used in this study, although none were of the same combinations tested here. Those hybrids included one intersectional cross between E. kruseana (sect. Bisectae ser. Kruseana) and E. ovularis (sect. Dumosae ser. Ovulares), 13 interseries crosses (12 within sect. Adnataria), and 11 intraseries crosses from ser. Curviptera and ser. Subulatae (both sect. Bisectae) and ser. Melliodorae and ser. Heterophloiae (both sect. Adnataria). The listings for recorded manipulated or spontaneous crosses were fewer (six), with five between species from different sections, including $E$. caesia (sect. Bisectae ser. Curviptera) and E. pulverulenta (sect. Maidenaria ser. Orbiculares), and one between species from different series in the same section.

Hybridization within eucalypts is often difficult to verify, as many naturally occurring and some spontaneously generated garden hybrids are observed as single individuals, often of uncertain parentage (e.g., Grayling and Brooker 1996; Rossetto et al. 1996; Delaporte et al. 2001), and where there is often evidence, either morphological or genetic, of backcrossing resulting in the offspring more resembling one of the parent species (Jordan et al. 1993; Potts and Jordan 1994; Sale et al. 1996; Jackson et al. 1999; Shelbourne et al. 1999). The long time to flowering can also make the morphological assessment of hybridity in offspring difficult or, at best, a long-term prospect, especially where there are longer-term problems with hy- brid fitness and survival (Lopez et al. 2000) or where the ratio of male to female parental dominance alternates within the first few years (Bouvet and Vigneron 1995, 1996), although predictive parental contribution based on multivariate morphological assessments is possible for some features (Baril et al. 1997a, 1997b). The current study found that at least for the seedling stage, the hybrid offspring with E. gillii as the mother were either intermediate or tended to resemble the mother (crosses with E. orbifolia and E. transcontinentalis), whereas nearly all the female E. socialis crosses showed apparent early maternal dominance. Whether this trend continues into maturity will remain to be seen.

The number of hybrids produced for each cross varied, with 203 hybrids from 246 seedlings measured, where E. gillii was the female parent from seven out of 15 crosses producing offspring. Offspring from E. socialis as the female parent produced 23 hybrids from 101 seedlings, measured from five out of 16 crosses producing offspring. The phylogenetic relationships between the species affected hybridization success, with intraseries crosses producing more hybrid seedlings than interseries and intersectional crosses. Lopez et al. (2000) found that in E. ovata $\times$ E. globulus hybrids, there was a significant reduction in hybrid fitness relative to the parents, with not only seedling deformity but also progressive mortality in young trees over time. This means that even though hybrids have been formed here and can be identified at early stages for further development, there is still no guarantee of their longterm survival, let alone horticultural merit.

In conclusion, this study shows that it is possible to produce a wide range of seedlings by crossing species from within $E \mathbf{~ - ~}$ calyptus subgenus Symphyomyrtus sections Bisectae and Adnataria and that seedling features and multivariate analysis are highly useful for the recognition and verification of hybrid seedlings in this group. The majority of the hybrid seedlings were intermediate between the maternal and pollen parents, although several, particularly those with E. socialis as the maternal parent, showed maternal dominance of morphological features. The methods used here are therefore useful for the first cull, early selection of hybrid seedlings for further horticultural development, but with the caveat that apparently desirable seedling features and/or those stemming from parental dominance may not necessarily carry through to the adult stage, so that subsequent selection and monitoring of progress will still be necessary.

\section{Acknowledgments}

We thank Jennifer Gardner for access to the Waite Arboretum and State Flora and Forestry South Australia for access to the Monarto Woodland. This research was supported by the Playford Memorial Trust and the Australian Landscape Trust.

\section{Literature Cited}

Baril CP, D Verhaegen, P Vigneron, JM Bouvet, A Kremer 1997a Structure of the specific combining ability between two species of Eucalyptus. 1. RAPD data. Theor Appl Genet 94:796-803.
$1997 b$ Structure of the specific combining ability between two species of Eucalyptus. 2. A clustering approach and multiplicative model. Theor Appl Genet 94:804-809. 
Beardsell DV, DL Jones, C Beardsell 1979 Early success with ornamental eucalypt breeding. Aust Plants 10:70-71.

Belbin L 1994 PATN pattern analysis package technical reference. Division of Wildlife and Ecology, CSIRO, Melbourne.

Bouvet JM, P Vigneron 1995 Age trends in variances and heritabilities in Eucalyptus factorial mating designs. Silvae Genet 44:206-216.

1996 Variance structure in Eucalyptus hybrid populations. Silvae Genet 45:171-177.

Brooker MIH 2000 A new classification of the genus Eucalyptus L'Hér. (Myrtaceae). Aust Syst Bot 13:79-148.

Brooker MIH, DA Kleinig 1999 Field guide to eucalypts. Vol 1. South Eastern Australia. 2d ed. Bloomings, Hawthorn, Victoria. 535 pp.

Delaporte K, JG Conran, M Sedgley 2001 Morphological analysis to identify the pollen parent of an ornamental interspecific hybrid Eucalyptus. Sci Hortic 89:57-74.

Eldridge K, J Davidson, C Harwood, G van Wyk 1993 Eucalypt domestication and breeding. Oxford University Press, New York. 288 pp.

Ellis M, M Sedgley, J Gardner 1991 Interspecific pollen-pistil interaction in Eucalyptus L'Hér. (Myrtaceae): the effect of taxonomic distance. Ann Bot 68:185-194.

Faith DP 1991 Effective pattern analysis methods for nature conservation. Pages 47-53 in CR Margules, MP Austin, eds. Nature conservation: cost effective biological surveys and data analysis. CSIRO, Melbourne.

Gore PL, BM Potts, PW Volker, J Megalos 1990 Unilateral crossincompatibility in Eucalyptus: the case of hybridisation between $E$. globulus and E. nitens. Aust J Bot 38:383-394.

Grayling PM, MIH Brooker 1996 Evidence for the identity of the hybrid Eucalyptus brachyphylla (Myrtaceae) from morphology and essential-oil composition. Aust J Bot 44:371.

Griffin AR, IP Burgess, L Wolf 1988 Patterns of natural and manipulated hybridisation in the genus Eucalyptus: a review. Aust J Bot 36:41-66.

Hodgson LM 1976 Some aspects of flowering and reproductive behaviour in Eucalyptus grandis (Hill) Maiden at J. D. M. Keet Forest Research Station. 1. Flowering, controlled pollination methods, pollination and receptivity. S Afr For J 97:18-28.

Hopper SD 1995 Evolutionary networks: natural hybridisation and its conservation significance. Pages 51-66 in DA Saunders, JL Craig, EM Mattiske, eds. Nature conservation: the role of networks. Surrey Beatty, Sydney.

Jackson HD, DA Steane, BM Potts, RE Vaillancourt 1999 Chloroplast DNA evidence for reticulate evolution in Eucalyptus (Myrtaceae). Mol Ecol 8:739-751.
Jordan GJ, BM Potts, JB Kirkpatrick, C Gardiner 1993 Variation in the Eucalyptus globulus complex revisited. Aust J Bot 41:763-785.

Ladiges PY 1997 Phylogenetic history and classification of eucalypts. Pages 16-29 in JE Williams, JCZ Woinarski, eds. Eucalypt ecology, individuals to ecosystems. Cambridge University Press, Cambridge.

Ladiges PY, F Udovicic 2000 Comment on a new classification of the eucalypts. Aust Syst Bot 13:149-152.

Lopez GA, BM Potts, PA Tilyard 2000 F1 hybrid inviability in the case of E. ovata $\times$ E. globulus. Heredity 85:242-250.

Minchin PR 1987 An evaluation of the relative robustness of techniques for ecological ordination. Vegetatio 69:89-107.

Ostrowska E, M Muralitharan, R Bassano 1998 In vitro propagation conditions for Eucalyptus ficifolia and E. citriodora. Aust Hortic 96:45-51.

Podani J 1999 Extending Gower's general coefficient of similarity to ordinal characters. Taxon 48:331-340.

Potts BM, GJ Jordan 1994 The spatial pattern and scale of variation in Eucalyptus globulus ssp. globulus: variation in seedling abnormalities and early growth. Aust J Bot 42:471-492.

Potts BM, RJE Wiltshire 1997 Eucalypt genetics and genecology. Pages 56-91 in JE Williams, JCZ Woinarski, eds. Eucalypt ecology, individuals to ecosystems. Cambridge University Press, Cambridge.

Pryor LD 1951 Controlled pollination of Eucalyptus. Proc Linn Soc N S W 76:135-139.

1956 An $\mathrm{F}_{1}$ hybrid between Eucalyptus pulverulenta and E. caesia. Proc Linn Soc N S W 81:97-100.

Pryor LD, LAS Johnson 1971 A classification of the eucalypts. Australian National University, Canberra. 54 pp.

Rossetto M, F Lucarotti, SD Hopper, KW Dixon 1997 DNA fingerprinting of Eucalyptus graniticola: a critically endangered relict species or a rare hybrid. Heredity 79:310-318.

Sale MM, BM Potts, AK West, JB Reid 1996 Molecular differentiation within and between Eucalyptus risdonii, E. amygdalina and their hybrids using RAPD markers. Aust J Bot 44:559-569.

Shelbourne CJA, SO Hong, R McConnochie, B Pierce 1999 Early results from trials of interspecific hybrids of Eucalyptus grandis with E. nitens in New Zealand. N Z J For Sci 29:251-262.

Tibbits WN 1988 Germination and morphology of progeny from controlled pollinations of Eucalyptus nitens (Deane and Maiden). Aust J Bot 36:677-691.

1989 Controlled pollination studies with shining gum (Eucalyptus nitens [Deane and Maiden] Maiden). Forestry 62:111-126.

Wirthensohn MG, G Collins, GP Jones, M Sedgley 1999 Variability in waxiness of Eucalyptus gunnii foliage for floriculture. Sci Hortic 82:279-288. 